\title{
Effect of Gas Phase Heat Sink on Suppression of Opposed Flow Flame Spread over Thin Solid Fuels in Microgravity Environment
}

\author{
Vinayak Malhotra, Chenthil Kumar, and Amit Kumar \\ Department of Aerospace Engineering, Indian Institute of Technology, Madras, Chennai 600036, India \\ Correspondence should be addressed to Amit Kumar, amitk@ae.iitm.ac.in
}

Received 30 March 2012; Accepted 20 September 2012

Academic Editor: Eliseo Ranzi

Copyright () 2012 Vinayak Malhotra et al. This is an open access article distributed under the Creative Commons Attribution License, which permits unrestricted use, distribution, and reproduction in any medium, provided the original work is properly cited.

\begin{abstract}
A two-dimensional numerical model of opposed flow flame spread over thin solid fuel is formulated and modeled to study the effect of gas phase heat sink (a wire mesh placed parallel to the fuel surface) on the flame-spread rate and flame extinction. The work focuses on the performance of the wire mesh in microgravity environment at an oxygen concentration $21 \%$. The simulations were carried out for various mesh parameters (wire diameter, " $\bar{d}_{\mathrm{wr}}$ " and number of wires per unit length, " $N$ ") and mesh distance perpendicular to fuel surface " $Y_{\text {mesh }}$ ". Simulations show that wire mesh is effective in reducing flame-spread rate when placed at distance less than flame width (which is about $1 \mathrm{~cm}$ ). Mesh wire diameter is determined not to have major influence on heat transfer. However, smaller wire diameter is preferred for better aerodynamics and for increasing heat transfer surface area (here prescribed by parameter " $N$ "). Flame suppression exhibits stronger dependence on number of wires per unit length; however, it is relatively insensitive to number of wires per unit length beyond certain value (here $20 \mathrm{~cm}^{-1}$ ).
\end{abstract}

\section{Introduction}

Diffusion flames formed over condensed fuels are well known to spread along the surface of the fuel by heat transfer from flame to fuel surface ahead of the flame. The heat transferred from the flame to the fuel pyrolyzes it to vapors which upon mixing with surrounding air form a combustible mixture. This combustible mixture is ignited by the flame behind and hence advances forward over the surface of the fuel. The study of flame spread phenomena is primarily driven by the need to have better fire safety, by means of enhanced understanding of the mechanisms that control the spread rates and extinction. Traditionally, the flame spread phenomena over solid fuels are studied under two basic categories: opposed flow flame spread and concurrent flow flame spread. This classification is based on the relative direction of flame spread with respect to the ambient gas velocity vector. In opposed flow flame spread, the flame spreads against the flow direction and in concurrent flow flame spread, the flame spreads in the direction of flow. Present work relates to the study of opposed flow spreading flame on thin solid fuel (cellulose sheets with area density $57 \mathrm{~g} / \mathrm{cm}^{2}$ ) in zero gravity.
Following the classical work of De Ris [1] on opposed flow spreading flames in 1969, over the last four decades research works have contributed significantly to the improvement in the understanding of the flame spread phenomena. The works [2-7] provide an excellent review on the developments up to the end of the century. In the past decade, more sophisticated experiments $[8,9]$ and more complex numerical approaches [10] in higher dimensions have been adopted to unravel the physics of flame-spread phenomena, yet complexity of problem due to nonlinear interactions between flow, heat and mass transfer along with chemistry in both solid and gas phases has prevented a complete understanding.

In almost all of flame-spread studies, a single fuel sheet is taken to understand the flame spreading mechanisms and flammability of solid materials. However, in practical situations, spreading flame may interact with nearby cold surfaces which will influence the flame-spread rates and extinction limits. This has not been investigated especially in microgravity where such interaction can have major implications. One such aspect which has not been addressed in the literature is the way flame-spread suppression can be affected 
by removing heat from the gas phase (here referred to as gas phase heat sink). The present work reports a study on the use of metallic wire mesh as gas phase heat sinks. Metal wire mesh when placed parallel to the fuel surface act as a flame extinguishing barrier by absorbing away heat from the flames and thus reducing heat feedback to unburnt fuel. If this heat feedback is reduced sufficiently, the pyrolysis of fuel will be reduced to the extent that the flame cannot self-sustain and therefore extinguishes. The aim of the study is to investigate the effectiveness of this gas phase heat sinks in suppressing flame and to examine the role of key controlling parameters.

\section{Computational Domain and Numerical Model}

Figure 1 shows the schematic of opposed flow flame spread configuration and the computational domain (bounded by dashed line). The governing equations are formulated in flame-fixed coordinates. Since the flame leading edge closely follows the pyrolysis front on the fuel surface, here the flamefixed coordinate system is located on the pyrolysis front $(X=0)$ of the solid where the fuel thickness is $95 \%$ of fresh fuel thickness. The flame leading edge is shown stabilized over the fuel near the origin with its tail extending downstream $(X<0)$. The free-stream-forced flow with uniform velocity $U \infty$ enters the domain at a distance $X_{\text {ent }}$ (referred to as flow entrance distance) from the origin. The flow approaches the flame (in negative $X$ direction) at a relative velocity of $\bar{U}_{R}(x, y)=\bar{U}(x, y)+V_{f}$, where $V_{f}$ is the flame spread rate and $\bar{U}(x, y)$ is the local velocity. The computational domain is subdivided into blocks in $X$ and $Y$ directions. Based on grid dependence study and requirement for accurate positioning of wire mesh above the fuel surface an optimized grid is generated for each of these blocks (a total of 122 grid points in $Y$ direction and 204 grid points in $X$ direction). The minimum grid sizes in $Y$ and $X$ directions are 0.001 and 0.005 thermal lengths respectively. Since the flame spread rate can change with time, the governing equations are written in noninertial frame of reference. These equations and major assumptions are written in noninertial frame of [11] and are described next. The assumptions made in modeling opposed flow flame spread over thin solids are listed below.

(1) The solid is assumed to be thin (both thermally and aerodynamically), for a thermally thin fuel the temperature is constant across its thickness. The aerodynamically thin condition implies that the flame standoff distance is much greater than the thickness of the solid so that the solid phase boundary conditions are applied at $Y=0$.

(2) As the flame spreads, the finite length of fresh fuel ahead of flame decreases in time. In present formulation flame spread is considered for fixed fuel length ahead of flame. This flame is assumed to represent the instantaneous flame in the inherently unsteady spread. This assumption holds if entrance length ahead of flame of gas is larger compared to the thermal length scale.

(3) The solid is assumed to burn ideally; that is, it vaporizes to form fuel vapors without melting or forming ash.

(4) The solid radiation is assumed to be diffuse.

(5) The flow velocities in this work are small $(<1-2 \mathrm{~m} / \mathrm{s})$ so the flow is assumed to be laminar.

2.1. Gas Phase Model. The gas phase model consists of twodimensional Navier-Stokes equations for laminar flow along with the conservation equations of mass, energy, and species. The specie equations are for fuel vapor, oxygen, carbon dioxide, and water vapor. The normalization procedure is similar to the one used by Kumar [12]. A one-step, second-order, finite rate Arrhenius reaction between fuel vapor and oxygen is assumed. The governing equations are presented in a nondimensional form. The nondimensional governing in the gas phase are summarized below.

Continuity equation:

$$
\frac{\partial \rho}{\partial t}+\nabla \cdot(\rho \vec{U})=0
$$

X-momentum equation:

$$
\begin{gathered}
\frac{\partial(\rho u)}{\partial t}+\nabla \cdot\left[\rho u \vec{U}-\left(\frac{\mu}{\mathrm{Re}}\right) \nabla u\right]=-p_{x}+\left(\frac{1}{\mathrm{Re}}\right) \\
\left\{\left[\frac{1}{3} \mu u_{x}-\frac{2}{3} \mu\left(v_{y}\right)\right]_{x}+\left[\mu v_{x}\right]_{y}\right\}+\left(\frac{U_{B}}{U_{R}}\right)^{3} \frac{\left(\rho-\rho_{\infty}\right)}{\left(\rho_{f}-\rho_{\infty}\right)} g \\
-\left(\frac{d V_{f}}{d t}\right) \frac{\left(\rho-\rho_{\infty}\right)}{\left(\rho_{f}-\rho_{\infty}\right)} .
\end{gathered}
$$

Y-momentum equation:

$$
\begin{gathered}
\frac{\partial(\rho v)}{\partial t}+\nabla \cdot\left[\rho v \vec{U}-\left(\frac{\mu}{\operatorname{Re}}\right) \nabla v\right]=-p_{y}+\left(\frac{1}{\operatorname{Re}}\right) \\
\left\{\left[\mu u_{y}\right]_{x}+\left[\frac{1}{3} \mu v_{y}-\frac{2}{3} \mu\left(u_{x}\right)\right]_{y}\right\},
\end{gathered}
$$

where $\operatorname{Re}=\bar{L}_{R} \bar{U}_{R} \rho^{*} / \mu^{*}, L_{R}=\alpha^{*} / \bar{U}_{R}, T_{R}=\left(L_{R}{ }^{*} L_{R}\right) / \alpha^{*}$, $\bar{U}_{R}=\bar{U}_{B}+V_{f}, \bar{U}_{B}=\left[g_{R} \beta_{R}\left(T_{\infty}-T_{F}\right) \alpha^{*}\right]^{1 / 3}$ is the reference buoyancy induced velocity.

Specie equation:

$$
\frac{\partial\left(\rho Y_{i}\right)}{\partial t}+\nabla \cdot\left[\rho Y_{i} \vec{U}-\left(\frac{1}{\operatorname{Le}_{i}}\right)\left(\rho D_{i} \nabla Y_{i}\right)\right]=\dot{\omega}_{i}^{\prime \prime \prime}
$$

$i=F, \mathrm{O}_{2}, \mathrm{CO}_{2}, \mathrm{H}_{2} \mathrm{O}, \mathrm{N}_{2}$.

$\mathrm{Le}_{i}=\bar{L}_{R}^{2} / D_{i}^{*} / \bar{L}_{R} / \bar{U}_{R}=\alpha^{*} / D_{i}^{*}$, Lewis number for species $i$, $\mathrm{Le}_{F i}=1.0, \mathrm{Le}_{\mathrm{O}_{2}}=1.11, \mathrm{Le}_{\mathrm{CO}_{2}}=1.39, \mathrm{Le}_{\mathrm{H}_{2} \mathrm{O}}=0.83, \mathrm{Le}_{\mathrm{N}_{2}}=$ $1.0, \dot{\omega}_{i}^{\prime \prime \prime}=f_{i} \dot{\omega}_{F}^{\prime \prime \prime}=f_{i} \operatorname{Da} \rho^{2} Y_{F} Y_{\mathrm{O}_{2}} \exp \left(-E_{g} / T\right)$, 


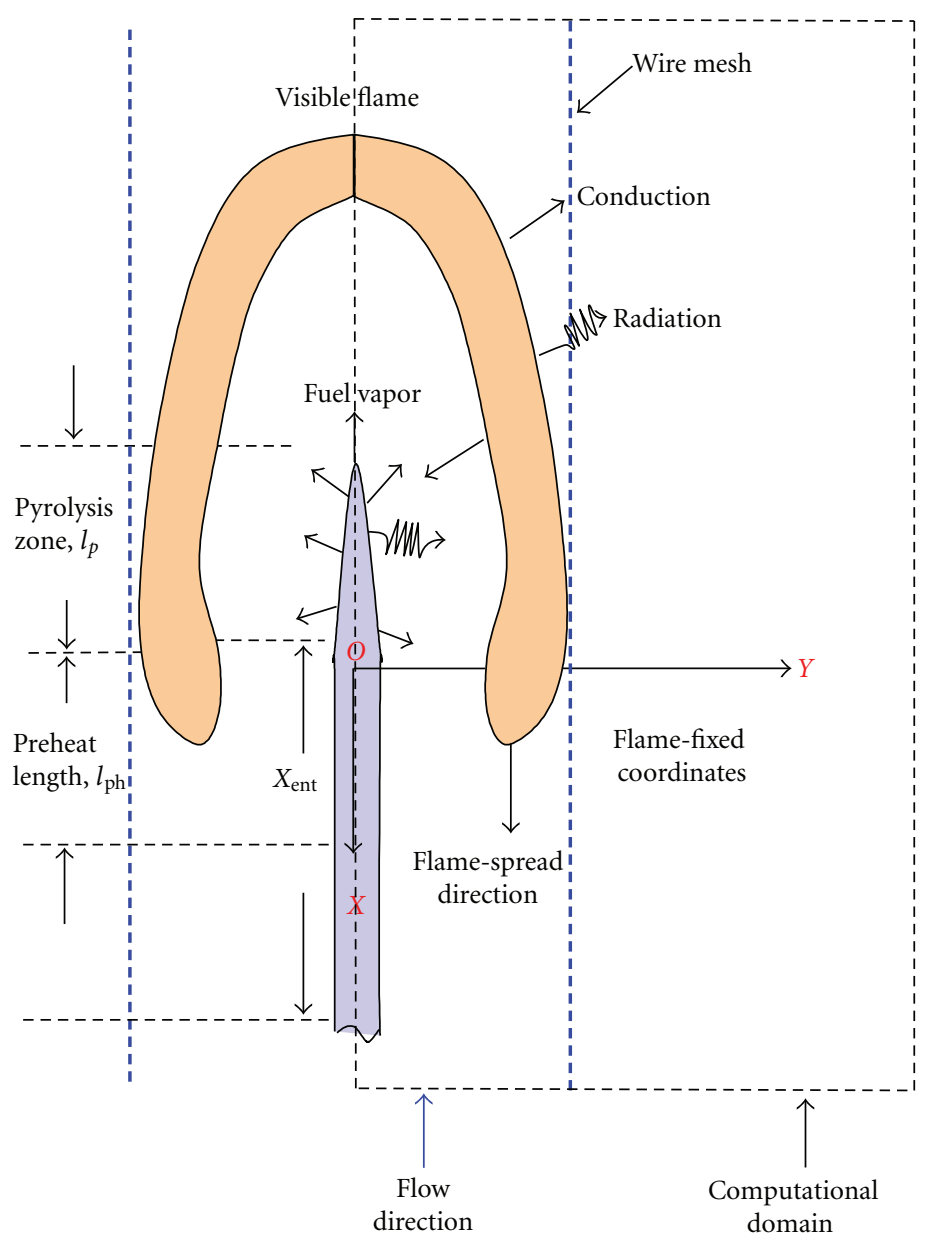

FIGURE 1: Schematic of a spreading flame over solid fuel and the computational domain.

where

$$
\begin{aligned}
\mathrm{Da} & =\frac{\text { characteristic flow time }}{\text { characteristic reaction time }} \\
& =\frac{\bar{L}_{R} / \bar{U}_{R}}{\rho^{*} / \rho^{* 2} \bar{B}_{g}}=\frac{\bar{B}_{g} \rho^{*} \alpha^{*}}{\bar{U}_{R}^{2}} .
\end{aligned}
$$

The stoichiometric combustion of fuel in air can be written as follows:

$$
\mathrm{C}_{6} \mathrm{H}_{10} \mathrm{O}_{5}+6\left(\mathrm{O}_{2}+3.76 \mathrm{~N}_{2}\right) \longrightarrow 6 \mathrm{CO}_{2}+5 \mathrm{H}_{2} \mathrm{O}+22.56 \mathrm{~N}_{2} \text {. }
$$

For the above one-step cellulose and air stoichiometric reaction, the stoichiometric ratios are

$$
\begin{gathered}
f_{F}=-1, \quad f_{\mathrm{O}_{2}}=-1.1852, \quad f_{\mathrm{CO}_{2}}=1.6296, \\
f_{\mathrm{H}_{2} \mathrm{O}}=0.5556, \quad f_{\mathrm{N}_{2}}=0 .
\end{gathered}
$$

\section{Energy equation:}

$$
\frac{\partial\left(\rho c_{p} T\right)}{\partial t}+c_{p} \nabla \cdot\left[\rho T \vec{U}-\left(\frac{\kappa}{c_{p}} \nabla T\right)\right]
$$

$$
\begin{aligned}
= & \sum_{i=1}^{N}\left(\frac{1}{\mathrm{Le}_{i}}\right) \rho D_{i} c_{p, i}\left(\nabla Y_{i} \cdot \nabla T\right)-\sum_{i=1}^{N} \dot{\omega}_{i}^{\prime \prime \prime} h_{i} \\
& +\nabla c_{p} \cdot \nabla T\left(\frac{\kappa}{c_{p}}\right)-\left(\frac{1}{B o}\right) \nabla: \vec{q}_{r}-\frac{Q_{\text {Sink }}}{A_{g}},
\end{aligned}
$$

where

$$
\begin{aligned}
c_{p} & =\sum_{i=1}^{N} c_{p, i} Y_{i}, \quad h_{i}=\frac{\left(\bar{h}_{i}^{0}+\int \bar{T}_{0} \bar{T}_{0}=298 K\right.}{\left(c_{p}^{*} \bar{T}_{\infty}\right)}, \\
B o & =\frac{\rho^{*} c_{p}^{*} U_{R}}{\left(\sigma T_{\infty}^{3}\right)} .
\end{aligned}
$$

The term $\nabla \cdot \vec{q}_{r}$ accounts for energy exchange due to radiative participating media. The radiative heat flux $\vec{q}_{r}$ is obtained from solution of the radiative transfer equation using discrete ordinate method. 
All thermal and transport properties are temperature dependent and are modeled following Smooke and Giovangigli [13]:

$$
\begin{aligned}
\frac{\mu}{\mu^{*}} & =\frac{\kappa / c_{p}}{\kappa^{*} / c_{p}^{*}}=\frac{\rho D_{i}}{\rho^{*} D_{i}^{*}}=\left(\frac{T}{T^{*}}\right)^{0.7}, \\
i & =F, \mathrm{O}_{2}, \mathrm{CO}_{2}, \mathrm{H}_{2} \mathrm{O}, \mathrm{N}_{2} .
\end{aligned}
$$

Here, $T^{*}(1250 \mathrm{~K})$ is the mean of the adiabatic flame temperature in air and ambient temperature.

The wire mesh is modeled as heat sink term in the energy equation but contributes no effect on the flow (momentum equation). The resistance to flow by mesh can be neglected if the mesh wire blockage in gas flow is not large (typically $<50 \%$ of mesh physical area). The heat flux absorbed by the mesh is modeled as

$$
\frac{Q_{\text {Sink }}}{A_{g}}=h \times \frac{A_{w}}{A_{g}} \times\left(T_{\text {gas }}-\bar{T}_{\text {surface }}\right),
$$

where $A_{w}$ denotes wire mesh heat transfer area and $A_{g}$ is the total mesh span area. $\bar{T}_{\text {surface }}$ is local temperature of the wire mesh. Since the flame propagates in direction opposite to the flow, it encounters mesh at ambient temperature, and since exposure time of mesh to the flame is small, $\bar{T}_{\text {surface }}$ is taken to be constant at $300 \mathrm{~K}$. Another consequence of constant wire temperature is that radiation from the wire can be neglected. While this assumption will over predict heat sink capacity of wire mesh, the results of parametric study carried out here are not likely to change as only relative improvement is sought. If the number of wires per unit length $(N)$ is the same in both directions then sink heat flux becomes

$$
\frac{Q_{\text {Sink }}}{A_{g}}=h \times\left(\pi \times \bar{d}_{\text {wr }} \times 2 N\right) \times\left(T_{\text {gas }}-\bar{T}_{\text {surface }}\right) .
$$

Here $h$ is the heat transfer coefficient for external transverse flow across cylindrical wires given by [14]

$$
h=\frac{k}{\bar{d}_{\mathrm{wr}}}\left[0.60+\frac{0.387 \mathrm{Ra}_{d_{\mathrm{wr}}}{ }^{1 / 6}}{\left[1+(0.559 / \mathrm{Pr})^{9 / 16}\right]}\right]^{2} .
$$

2.2. Solid-Phase Model. The thin solid fuel model comprises equations of continuity and energy in one-dimension along with a solid fuel pyrolysis law. The solid is assumed to burn ideally; that is, it vaporizes to form fuel vapors without melting or charring, which holds true for thin cellulosic fuels, where flame spread rate is dictated by combustion of volatiles and not by slow combusting of char [15]. The solid considered here is a cellulosic material with half thickness $\tau=$ $0.0038 \mathrm{~cm}$ and density $0.75 \mathrm{~g} / \mathrm{cm}^{3}$. The pyrolysis of fuel is modeled using a one-step, zeroth-order, Arrhenius kinetics, and the radiation loss from the solid is included. The pyrolysis model relating fuel vapor mass flux from the solid to the surface temperature can be represented as follows:

$$
\dot{m}=A_{s} \rho_{s} \exp \left(\frac{-E_{S}}{T_{S}}\right)=\rho v_{w} .
$$

The governing equations in solid phase are as follows.
Mass conservation:

$$
\rho_{s} V_{f}(h)_{x}-\dot{m}=\rho_{s} \frac{\partial h}{\partial t} .
$$

Relation between fuel thickness and surface temperature is obtained as

$$
(h)_{x}=\frac{A_{s}}{V_{f}} \exp \left(\frac{-E_{s}}{T_{s}}\right)+\frac{1}{V_{f}} \frac{\partial h}{\partial t} .
$$

Energy equation:

$$
\begin{gathered}
q_{c}+\frac{q_{r}^{y}}{B o}+\Gamma\left(h T_{s}\right)_{x}-\Gamma(h)_{x} \\
{\left[(1-c) T_{L}+(-L)+c T_{S}\right]=\rho_{s} c_{s} \frac{\partial\left(T_{s} h\right)}{\partial t},}
\end{gathered}
$$

where $\Gamma=\bar{\rho}_{s} \bar{c}_{s} V_{f} / \rho^{*} c_{P}^{*} \bar{U}_{R}$.

The kinetic parameters in gas-phase and solid-phase models are taken from work of Tolejko et al. [16].

\section{Boundary Conditions}

The elliptic nature of the governing equation for the gas phase requires prescribing information at all the boundaries. These boundary conditions are mentioned below.

AT $X=x_{\max }$ (upstream or inlet)

$$
\begin{gathered}
u=\frac{\left(\bar{U}_{\infty}-V_{f}\right)}{\bar{U}_{R}}, \quad v=0 \\
T=1, \quad Y_{\mathrm{O}_{2}}=Y_{\mathrm{O}_{2} \text {,inlet }}, \quad Y_{i}=0 \quad\left(i=F, \mathrm{CO}_{2}, \mathrm{H}_{2} \mathrm{O}\right) .
\end{gathered}
$$

At $X=x_{\text {min }}$ (downstream or exit)

$$
u_{x}=0, \quad v_{x}=0
$$

$$
\text { If } u>0, \quad T=1, \quad Y_{\mathrm{O}_{2}}=Y_{\mathrm{O}_{2}, \infty}, \quad Y_{i}=0,
$$

where $i=\mathrm{CO}_{2}, \mathrm{H}_{2} \mathrm{O}, F$.

$$
\text { If } u \leq 0, \quad T_{x}=0, \quad\left(Y_{i}\right)_{x}=0,
$$

where $i=\mathrm{O}_{2}, \mathrm{CO}_{2}, \mathrm{H}_{2} \mathrm{O}, F$

At $Y=0$ (fuel surface or $Y$ symmetry plane)

$$
\begin{aligned}
& u=-\frac{V_{f}}{\bar{U}_{R}}, \quad v=v_{w}, \quad T=T_{s} \\
& \dot{m} Y_{F, w}=\dot{m}+\frac{\rho D_{F}}{\operatorname{Le}_{F}}\left(\frac{\partial Y_{F}}{\partial y}\right)_{w},
\end{aligned}
$$

$$
\dot{m} Y_{i, w}=\frac{\rho D_{i}}{\mathrm{Le}_{i}}\left(\frac{\partial Y_{i}}{\partial y}\right)_{w} \quad\left(i=\mathrm{O}_{2}, \mathrm{CO}_{2}, \mathrm{H}_{2} \mathrm{O}\right) .
$$


At $Y=y_{\max }$ (far field boundary)

$$
\begin{gathered}
u=-\frac{V_{f}}{\bar{U}_{R}}, \quad v_{y}=0, \quad v_{y}=0, \\
\text { if } v>0: T_{Y}=0, \quad\left(Y_{\mathrm{O}_{2}}\right)_{y}=0, \quad\left(Y_{i}\right)_{y}=0, \\
\text { if } v<0: T=1, \quad Y_{\mathrm{O}_{2}}=Y_{\mathrm{O}_{2}}, \quad Y_{i}=0,
\end{gathered}
$$

where $i=F, \mathrm{CO}_{2}, \mathrm{H}_{2} \mathrm{O}$.

The boundary conditions for the solid phase governing equations are the prescribed fuel thickness and the surface temperature at fuel leading edge upstream of flame at $x=$ $x_{\min }, T_{s}=1, h=\bar{\tau} / \bar{L}_{R}$.

Here the fuel vapor mass flux $\dot{m}$, blowing velocity $v_{w}$, and surface temperature $T_{s}$ as functions of $x$ and $z$ are determined by the coupled solutions of the solid-phase equations.

\section{Gas Radiation Model and Boundary Conditions}

A direct treatment of radiation involves solving the radiative transfer equation (RTE) for intensity distribution over the field of interest. The RTE is solved by the discrete ordinates method using the quadrature set from Balsara [17]. The transfer equation for radiation energy (in nondimensional form) passing in a specified direction $\vec{\Omega}$ through a small differential volume in an emitting, absorbing and nonscattering gray medium, in two-dimensional coordinates can be written in $\mathrm{S}-\mathrm{N}$ approximation as

$$
\begin{aligned}
& \xi \frac{\partial I(x, y, \Omega)}{\partial x}+\eta \frac{\partial I(x, y, \Omega)}{\partial y}+\beta(x, y) I(x, y, \Omega) \\
& =\alpha(x, y) I_{b}(x, y)+\frac{\sigma}{4 \pi} \int_{w_{i}=4 \pi} I\left(x, y, \Omega_{i}\right) d \Omega_{i},
\end{aligned}
$$

where ordinate $m=1,2, \ldots, M$.

$\xi, \eta=$ direction cosines in $x$ and $y$ direction and the number of ordinates, $M=2^{k}\left(N_{o}\left(N_{o}+2\right)\right) / 8$, where " $k$ " is the number of dimension, $K$ is the absorptivity of the medium, and " $N_{o}$ " is the order of S-N method.

The finite difference equation of the S-N discrete ordinates equation can be written as follows:

$$
\begin{gathered}
\xi^{m}\left[A_{e} I_{e}{ }^{m}-A_{w} I_{w}{ }^{m}\right]+\eta^{m}\left[A_{n} I_{n}{ }^{m}-A_{s} I_{s}{ }^{m}\right]+\Delta V \cdot K \cdot I_{p}{ }^{m} \\
=\Delta V \cdot K\left(I_{b}\right)_{p} .
\end{gathered}
$$

As for the boundary condition, the outgoing radiation intensity from the wall can be expressed as

$$
\begin{aligned}
I\left(r_{w}, \Omega\right)= & \varepsilon\left(r_{w}\right) I_{b}\left(r_{w}\right)+\frac{(1-\alpha)}{\pi} \\
& \times \int_{n \Omega^{\prime}<0}^{\infty}\left|n \cdot \Omega^{\prime}\right| I\left(r_{w}, \Omega^{\prime}\right) d \Omega^{\prime}, \quad n \cdot \Omega>0,
\end{aligned}
$$

where $\varepsilon, \alpha$ emissivity and absorptivity of the wall surface.
Once the radiation intensity field is obtained, the total incident radiation, radiative flux, and the divergence of radiative flux in the rectangular domain is obtained from the following formulae.

The incident radiation can be written in S-N approximation as

$$
G(x, y)=\int_{4 \pi} I(x, y, \Omega) d \Omega \cong \sum_{m=1}^{M} w^{m} I^{m}(x, y) .
$$

The divergence of radiative flux for the assumptions of emitting, absorbing and nonscattering gray is shown below:

$$
\nabla \cdot q_{r}(x, y)=\alpha(x, y)\left[4 \sigma T^{4}(x, y)-G(x, y)\right] .
$$

It was mentioned earlier that the mean absorption coefficient $K(x, y)$ for the gas mixture is needed. In this work, soot is assumed to be absent so the participating gases are carbon dioxide and water vapor. One-dimensional studies by Bedir et al. [18] and Rhatigan et al. [19] have shown that even for a flame as thin as one or two centimeters, the flame is not optically thin. This is because the self-absorption of the gaseous species in their radiating bands. By comparison with the more accurate results obtained from a narrowband radiation model in one-dimensional flames, it was shown that the Planck-mean results overpredict net emission from the flame $[18,19]$. To improve the computed heat flux at the surface or ambient, a correction is needed. One such procedure has been proposed in [19] and is adopted in this work. This procedure is described briefly below. The local Plank-mean absorption coefficient for the mixture can be given by $K_{p}=$ $P_{\mathrm{CO}_{2}} \cdot K_{p\left(\mathrm{co}_{2}\right)}+P_{\mathrm{H}_{2} \mathrm{O}} \cdot K_{p\left(\mathrm{H}_{2} \mathrm{o}\right)}$, where $P_{i}$ represents the partial pressure of species $i$. The values of $K_{p}$ for each species are from Tien [20] as a function of temperature. A novel feature used here is the incorporation of a calibration procedure [19] for the mean absorption coefficient. The calibration of the absorption coefficient against the narrowband results through a quasi-one-dimensional flame is to account for the different optical lengths in different part of the flame and the effect of spectral self-absorption of gaseous species. Therefore the local absorption coefficient $K$ used in this work is set to equal to $K(x, y, z)=C K_{p}$, where $C$ is the correction factor. In the downstream flame region of $X>0, C$ is determined by an optical traverse in the $Y$-direction (perpendicular to the solid) and using empirical relation proposed in [19]. For the region of $X<0$ where the flame is highly two-dimensional, two traverses are made from $X=0$, one in the $Y$-direction and the other in $X$-direction toward upstream.

\section{Numerical Solution Methodology}

The system of coupled partial differential equations for the flow and combustion in the gas phase is solved numerically by SIMPLER algorithm [21]. The nonlinear equations are discretized using finite-volume-based difference technique. The velocities are stored at staggered grid locations with respect to the scalar. The resulting set of algebraic equations is solved by sweeping plane-by-plane in each direction. 


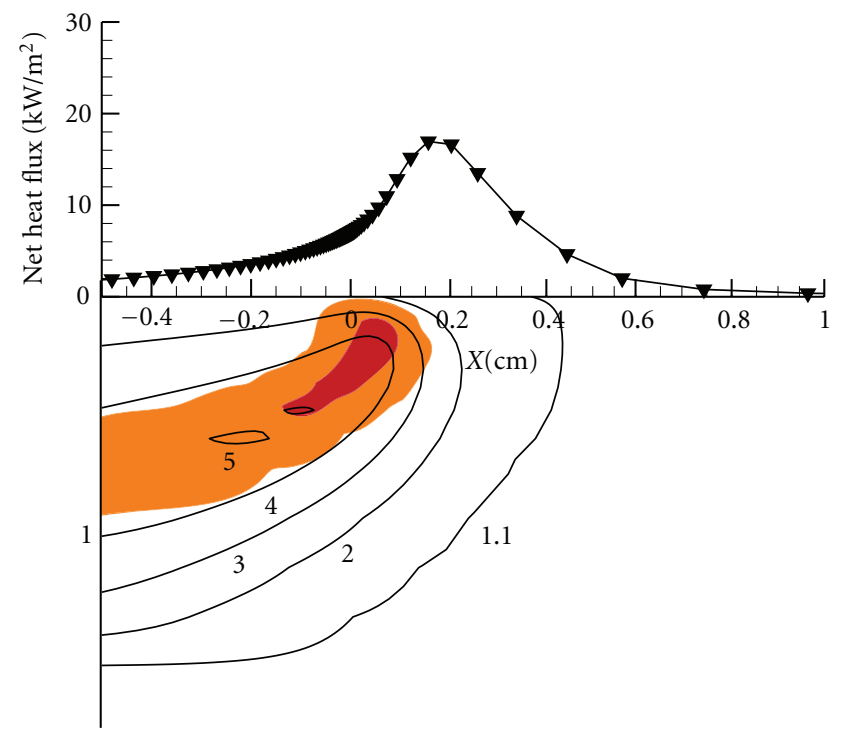

FIGURE 2: Computed flame (shaded region); temperature field (bottom) (1 unit = $300 \mathrm{~K})$; and net heat flux on the fuel surface.

Along each plane, the line-by-line procedure is used, which is a combination of Gauss-Seidel and the tridiagonal matrix algorithm (TDMA). The gas-phase system is coupled with the sold-phase equations, which are solved by finitedifference technique. The gas- and solid-phase equations are solved in turn; each provides input in the form of boundary conditions for the other. Steady-flame spread is an Eigen value, which is determined iteratively using bisection method by forcing the pyrolysis front (95\% of the fresh fuel thickness) to occur at $X=Y=0$.

\section{Results}

The simulations were carried out for slow forced flow with a velocity of $10 \mathrm{~cm} / \mathrm{s}$ in microgravity environment with $21 \%$ $\mathrm{O}_{2}$ on cellulose sheets with area density 57 gsm (grams per square meter). The flame spreads in downward direction, and according to classical heat transfer theory on flame spread [22] over thin solid fuel, the opposed flow propagating flame spreads by heat feedback from the flame to the solid fuel upstream of the flame. The present model was extensively validated against experimental data in both microgravity environments [10] and in normal gravity $\left(1 g_{e}\right)$ [23], where a numerical study supported by experiments was carried out on flame inhibition by wire mesh of downward spreading flame. Thus, the present model is expected to offer reasonable prediction and physical insight into the flame suppression of microgravity-opposed flow spreading flame for experimental data which is not available in the literature. Figure 2 shows in detail the computed flame structure. The flame width (maximum distance of flame from the fuel surface) is about $1 \mathrm{~cm}$. The computed flame is shown as shaded region bounded by reaction rate contour of $10^{-4} \mathrm{~g} / \mathrm{cm}^{3} / \mathrm{s}$ [24]. Figure 2 also shows spatial distribution of flame temperature (nondimensionalized to ambient temperature of $300 \mathrm{~K}$ ). The hottest region of the flame is located approximately in the midway of the reaction zone. In the upper half of Figure 2 local net heat flux (which is sum total of the conductive and radiative heat fluxes) from the gas phase to the fuel surface along the surface of the fuel surface is presented. One can note that the net heat flux reaches a maximum near the flame leading edge where flame is close to the surface and trails off in both upstream and downstream directions. As mentioned above the flame spread rate is directly proportional to the integrated net flux ahead (upstream) of flame (i.e., for all $x>0$ ). Here we have presented only an illustrative numerical prediction. A more rigorous comparison can be found in [10].

In the presence of metallic wire mesh, a part of heat generated in flame will be absorbed by the wire and thus affect heat feedback to the fuel surface. If this heat feedback is reduced sufficiently the flame will extinguish. From the expression for $Q_{\text {Sink }} / A_{g}(11)-(13)$ we see that the only mesh parameter that influences the sink heat flux is " $N$ " (number of wires per unit length). It is understood from the formulation (11)-(13) that, although the effect of parameter wire diameter $\left(\bar{d}_{\mathrm{wr}}\right)$ is present, it is not expected to have a major influence on heat transfer. Apart from mesh parameters the position of mesh $\left(Y_{\text {mesh }}\right)$ with respect to fuel surface is an important parameter. First a set of computations were performed for mesh-wire diameters $\left(\bar{d}_{\mathrm{wr}}\right)$ of $0.010 \mathrm{~cm}$ for numbers of wires per unit length $(N)$ of $5 \mathrm{~cm}^{-1}$ and $40 \mathrm{~cm}^{-1}$ placed at various distances above the fuel surface. It should be mentioned here that for a given wire diameter $\left(\bar{d}_{\mathrm{wr}}\right)$ increasing " $N$ " decreases the flow area for the gases to pass through the mesh and also increase the resistance to the flow. This means that for thicker wire diameter, the limiting value of " $N$ " (for blockage fraction <50\%) would be lesser compared to thinner diameter wires. Therefore, even though 
the heat transfer to the wire mesh is nearly independent of mesh wire diameter, the selection of smaller diameter wires will allow a larger " $N$ " with minimal resistance to the gases flowing across the mesh. This in turn is expected to have larger bearing on heat transport to the wire mesh. Based on the above-mentioned reasons a wire mesh wire diameter of $0.010 \mathrm{~cm}$ was selected for further computations.

The effects of wire mesh location $\left(Y_{\text {mesh }}\right)$ and number of wires per unit length $(N)$ on suppression of spreading flame are explored next. Figure 3 presents nondimensional temperature contours ( 1 unit $=300 \mathrm{~K}$ ) and visible flame (shaded region enclosed by reaction rate contour $10^{-4} \mathrm{~g} / \mathrm{cm}^{3} / \mathrm{s}$ ) in presence of wire mesh with wire diameter of $0.0010 \mathrm{~cm}$. Two types of mesh, thin with $N=5 \mathrm{~cm}^{-1}$ (Figure 3(a)) and dense with $N=40 \mathrm{~cm}^{-1}$ (Figure $3(\mathrm{~b})$ ) are shown placed at $1.30 \mathrm{~cm}$, $1.0 \mathrm{~cm}, 0.90 \mathrm{~cm}$, and $0.75 \mathrm{~cm}$. One can note that since the flame width (height above fuel surface) is about $1 \mathrm{~cm}$, placing of mesh at distances larger than $1 \mathrm{~cm}$ has small effect on flame shape and spatial temperature distribution. At distances below $1 \mathrm{~cm}$, flame is seen to shrink in size and have lower temperatures. However, a drastic drop in flame size is observed only at distances below $0.90 \mathrm{~cm}$ for $N=40 \mathrm{~cm}^{-1}$ and $0.75 \mathrm{~cm}$ for $N=5 \mathrm{~cm}^{-1}$. It is also noted that higher values of " $N$ " (here say $N=40 \mathrm{~cm}^{-1}$ ) which have larger heat transfer area are more effective in reducing the maximum flame temperature compared to wire mesh with lower " $N$ " values (here $N=5 \mathrm{~cm}^{-1}$ ).

The effectiveness of wire mesh in suppressing the flame is also reflected in the reduction of net heat flux to the solid fuel. Figure 4 shows the net heat flux over solid fuel surface for mesh with $N=5 \mathrm{~cm}^{-1}$ (Figure $4(\mathrm{a})$ ) and $N=40 \mathrm{~cm}^{-1}$ (Figure 4(b)). Reduced heat fluxes are a consequence of reduced gas temperatures and therefore follow the trend seen in Figure 3. It is seen that reduction in net heat flux is more for higher values of " $N$ " $\left(>20 \mathrm{~cm}^{-1}\right)$ and shorter mesh distance $(<0.90 \mathrm{~cm})$. It is interesting to note that the net heat flux curves for wire mesh placed above flame width $(>0.90 \mathrm{~cm})$ are quite close to the net heat flux curve when there is no inhibition. This suggests that heat removal from the flame-leading edge is most effective compared to any other location in the flame.

The flame-spread rate is directly proportional to the integrated net heat flux over the preheat region of the fuel. Therefore, the flame-spread rate reduction will follow the trend observed in net heat flux to the solid fuel surface. Figure 5 shows the variation of spread rates with mesh distance for $N=5 \mathrm{~cm}^{-1}, 10 \mathrm{~cm}^{-1}, 20 \mathrm{~cm}^{-1}$, and $40 \mathrm{~cm}^{-1}$. It is seen that the spread rates change significantly for the mesh placed below $1.3 \mathrm{~cm}$. The spread rates begin to drop with increasing steepness for mesh distance below $0.90 \mathrm{~cm}$. It is interesting to note that decrement in spread rates is steeper for the mesh with higher " $N$." Flame extinction was observed at certain minimum mesh distance from the fuel surface which ranged from $0.44 \mathrm{~cm}$ (for $N=5 \mathrm{~cm}^{-1}$ ) to $0.61 \mathrm{~cm}$ (for $N=40 \mathrm{~cm}^{-1}$ ). It should be pointed out here that in the preceding study [23] with downward spreading flame the minimum mesh distance for all mesh densities were between $0.15-0.17 \mathrm{~cm}$. Thus while for normal gravity downward spreading flame the minimum distance was nearly independent of mesh density, here we see that extinction distances show a stronger dependency on wire mesh density " $N$." Further it is interesting to note that for $N=$ $20 \mathrm{~cm}^{-1}$ and $N=40 \mathrm{~cm}^{-1}$, the flame-spread rates at various mesh locations and the extinction distances (here at $0.60 \mathrm{~cm}$ to $0.61 \mathrm{~cm}$, resp.) are very close. For lower values of " $N$ " these values are spread over a wider range. This suggests that $N=$ $20 \mathrm{~cm}^{-1}$ mesh density is enough to extract heat at any mesh location up to flame extinction.

It should be noted reaction described here by use of a global kinetics. The use of detailed kinetics will differ in the spatial heat release in the flame [25]. It is reported [25] that the peak heat release rates are closer to the fuel surface for detailed chemistry model [25]. Therefore, the above-mentioned distances are expected to be predicted lower from detailed kinetics compared to the global kinetics.

Since " $N$ " was seen to have strong influence on flame spread rate, further simulations were carried out at mesh locations of $0.75 \mathrm{~cm}$ and at distance near to extinction for " $N$ " values of $5 \mathrm{~cm}^{-1}, 10 \mathrm{~cm}^{-1}, 20 \mathrm{~cm}^{-1}$, and $40 \mathrm{~cm}^{-1}$. Similar to the plots of Figure 3, Figure 6 presents temperature contours and reaction rate contours for mesh distance of $0.75 \mathrm{~cm}$ from the fuel surface (Figure 6(a)) and at mesh distance close to extinction distance (Figure 6(b)). Lower maximum temperature and smaller flames are seen for meshes with higher " $N$ " indicating increasing heat sink effect with increase in " $N$." In Figure 6(b) for $N=5 \mathrm{~cm}^{-1}$ flame spilled out of wire mesh but increasing " $N$ " $\left(N>20 \mathrm{~cm}^{-1}\right)$ contained flame between the mesh and fuel surface. However, at near extinction distances from the fuel surface, the flame was always contained between the mesh and the fuel surface. The reason for this can attributed to the fact discussed above that the wire mesh is close to the leading edge which primarily controls the flame spread phenomena. Temperature reduction in the flame-leading edge region drastically reduces the highly temperature sensitive reaction rates.

Figure 7 shows net heat flux along the fuel surface observed for cases presented in Figure 6. Figure 7(a) shows that net heat flux profiles at wire mesh location of $0.75 \mathrm{~cm}$, and Figure 7 (b) shows the net heat flux profiles at wire mesh distances from fuel surface close to flame extinction locations. Inserting mesh at distance of $0.75 \mathrm{~cm}$ from the fuel surface, even with less dense mesh as $N=5 \mathrm{~cm}^{-1}$ results in drastic reduction in local net heat flux values once again confirming that leading edge is the location heat sink will be most effective. Further increase in " $N$ " reduces local net heat flux; however, one can note that for $N=20 \mathrm{~cm}^{-1}$ and $40 \mathrm{~cm}^{-1}$ the net heat flux profiles are significantly lower than for the case of $N=5 \mathrm{~cm}^{-1}$ and $10 \mathrm{~cm}^{-1}$. This indicates decreasing gains in terms of heat sink effect by increasing " $N$ " and that $N=20 \mathrm{~cm}^{-1}$ is sufficient to remove extractable heat at this location and further increase in " $N$ " here is redundant. Further, it is interesting to note that at near extinction the net heat flux profiles for all cases of Figure 7(b) are practically identical indicating a weaker dependence on $N$ (here for $N>5 \mathrm{~cm}^{-1}$ ) in determining flame extinction. This fact again emphasizes the importance of heat extraction from flame leading edge is most effective. 

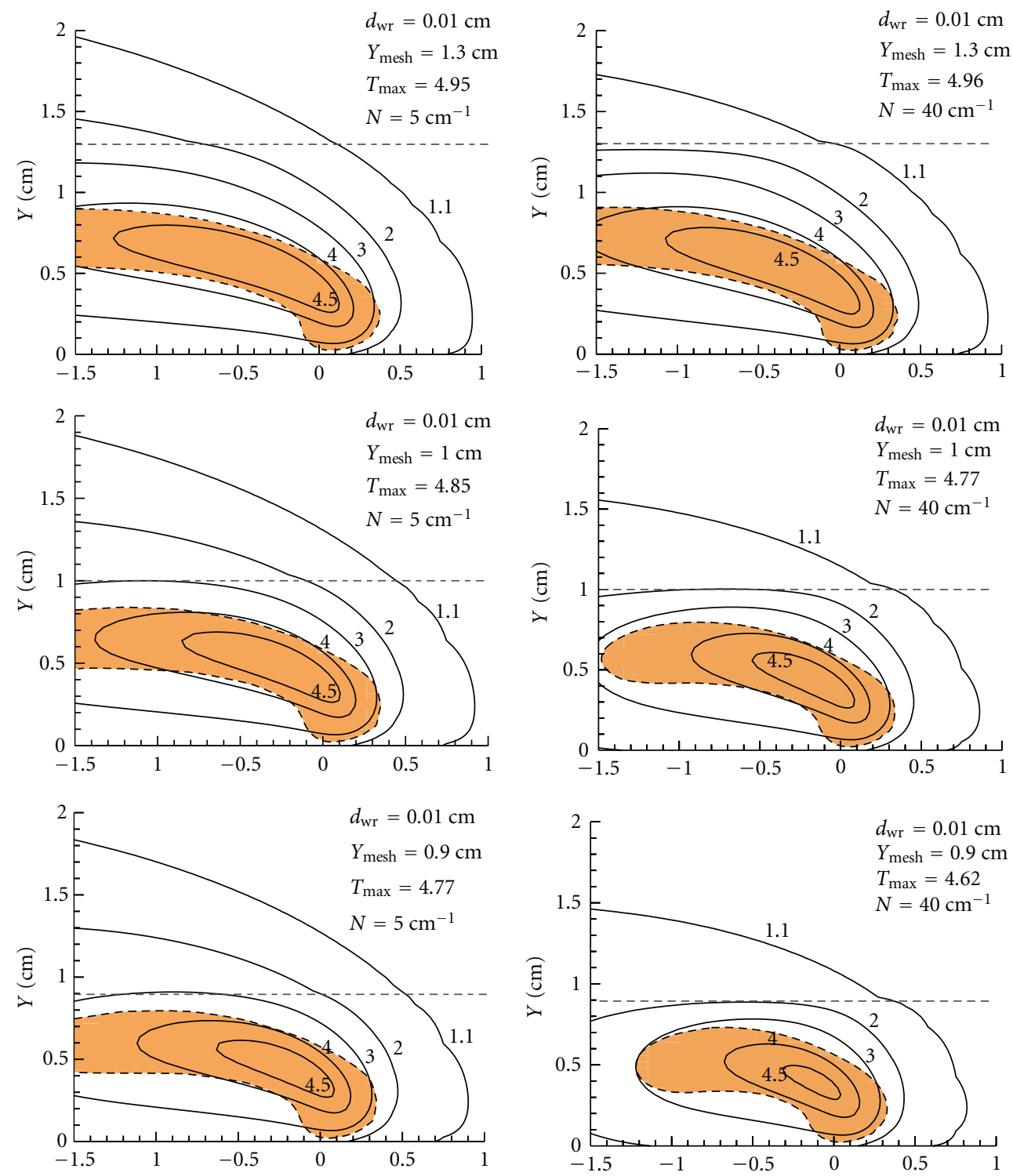

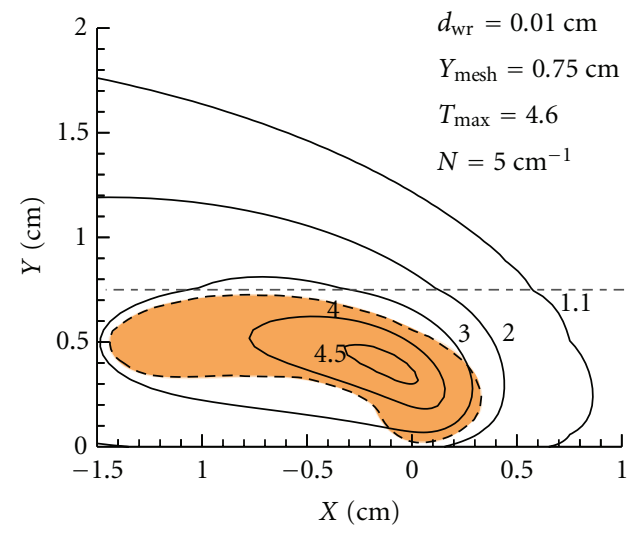

(a)

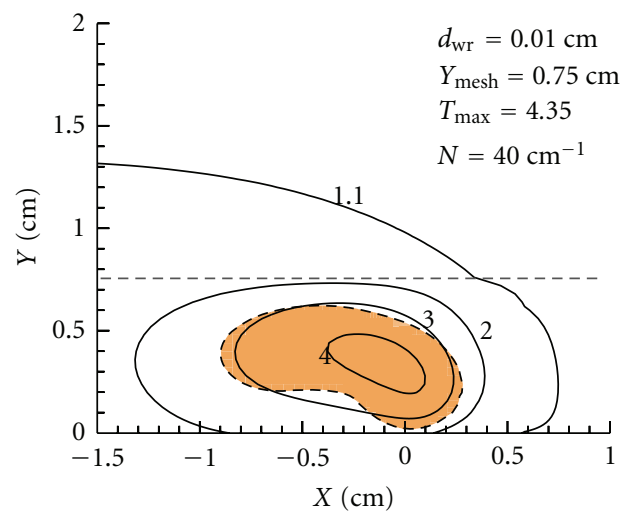

(b)

FIgURE 3: Effect of $N$ and $Y_{\text {mesh }}$ on flame size and temperature field-(a) $N=5 \mathrm{~cm}^{-1}$ and; (b) $N=40 \mathrm{~cm}^{-1}$. The dashed line represents wire mesh. 


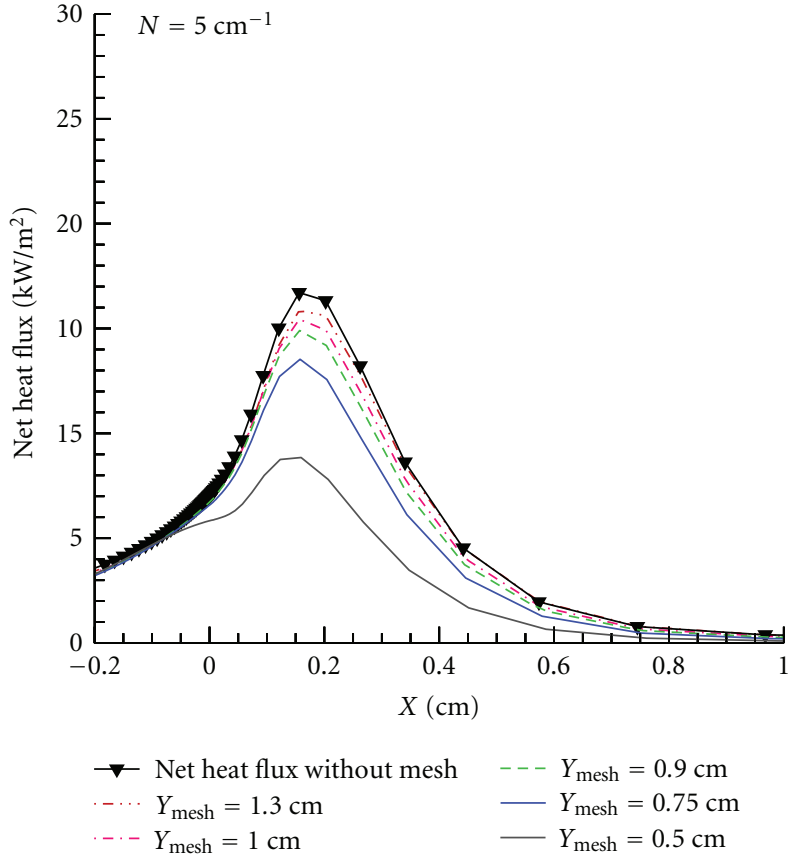

(a)

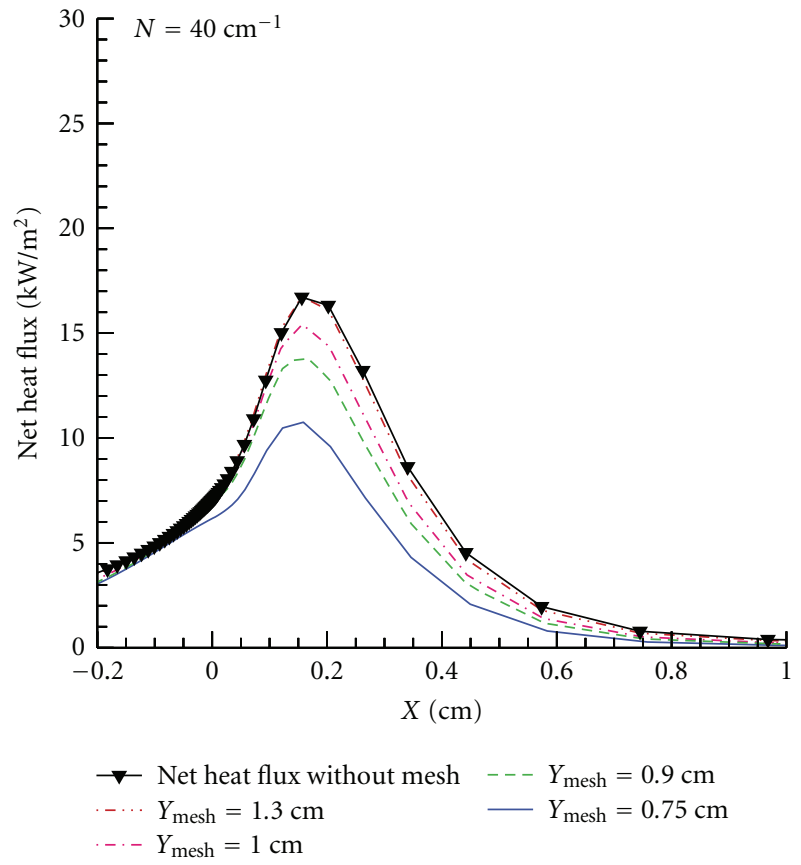

(b)

Figure 4: Effect of $N$ and $Y_{\text {mesh }}$ on net heat flux (a) $N=5 \mathrm{~cm}^{-1}$ (b) $N=40 \mathrm{~cm}^{-1}$.

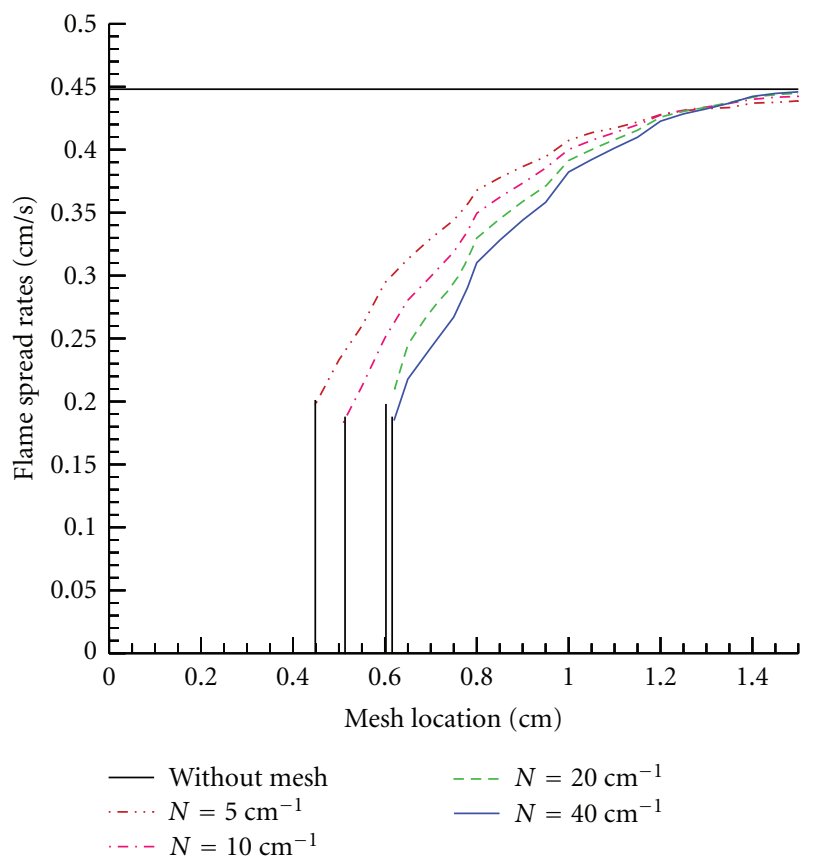

Figure 5: Effect of metallic wire mesh on flame spread rates.

\section{Conclusions}

The numerical model for opposed flow spreading flame is formulated and modeled to study gas phase heat sink effect of metallic wire mesh placed parallel to a thin fuel surface in microgravity ambient environment of $21 \%$ oxygen concentration. The study was carried out with primary objective of analyzing the effectiveness of wire mesh in retarding flamespread rate and inducing flame extinction. The influence of mesh variables, namely, mesh wire diameter $\left(\bar{d}_{\mathrm{wr}}\right)$, number of wires per unit length $(N)$, and mesh distance from fuel surface $\left(Y_{\text {mesh }}\right)$ was investigated, and following conclusion may be drawn for this study.

(1) The wire mesh is not effective when placed at location above flame width (which is typically about $1 \mathrm{~cm}$ ).

(2) Wire mesh when placed typically at distance $<0.75 \mathrm{~cm}$ (of the order of reference length, $\alpha^{*} / \bar{U}_{R}$ ) above the fuel surface is most effective in suppressing flame to extinction. At this location flame suppression exhibits stronger dependence on " $N$ " (number of wires per unit length).

(3) The mesh placed at a given distance from fuel surface with larger number of wires per unit length (" $N$ ") is more effective in reducing flame-spread rate for same operating conditions. However, the heat sink advantage of increasing " $N$ " comes with diminishing returns. Therefore, beyond certain value (here $20 \mathrm{~cm}^{-1}$ ), increasing " $N$ " would not be very effective.

(4) Mesh wire diameter is determined not to have major influence on heat transfer. However, smaller wire diameter is preferred for better aerodynamics and for increasing heat transfer surface area (here prescribed by parameter " $N$ ").

Here we note that the fuel Lewis number was assumed to be unity. This was assumed as the exact products of pyrolysis 

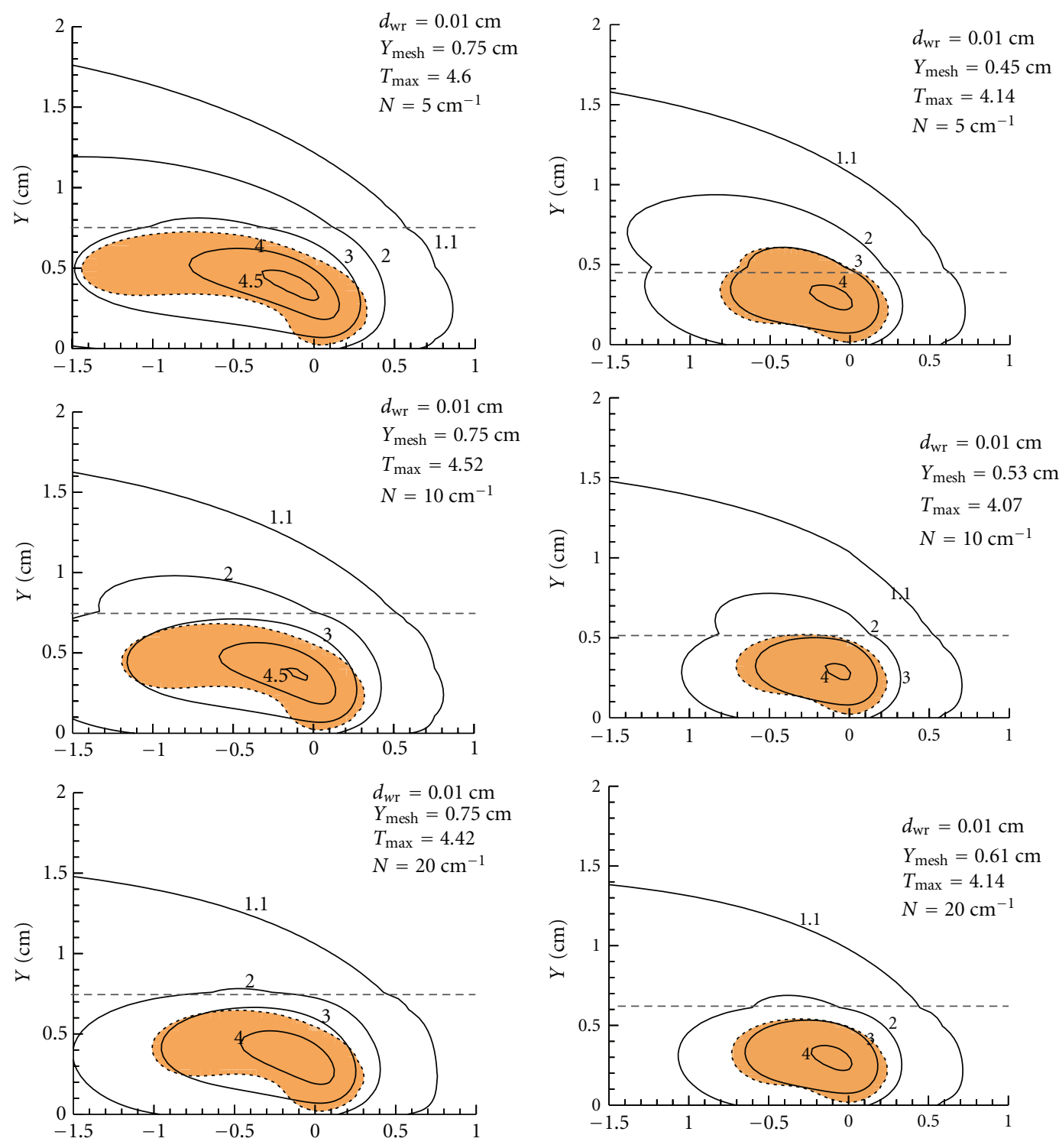

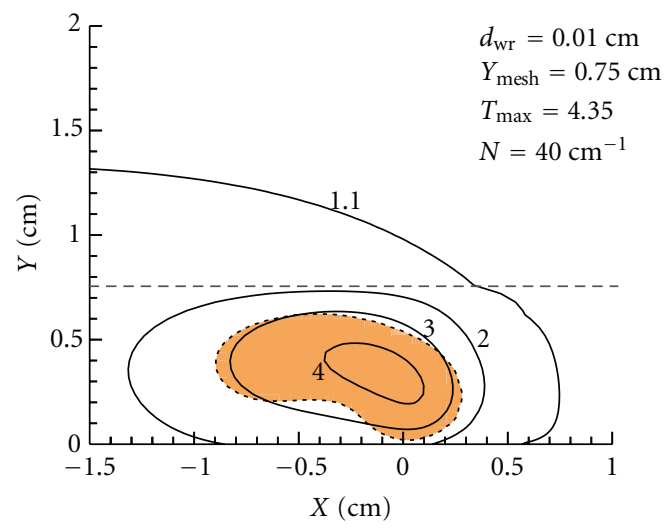

(a)

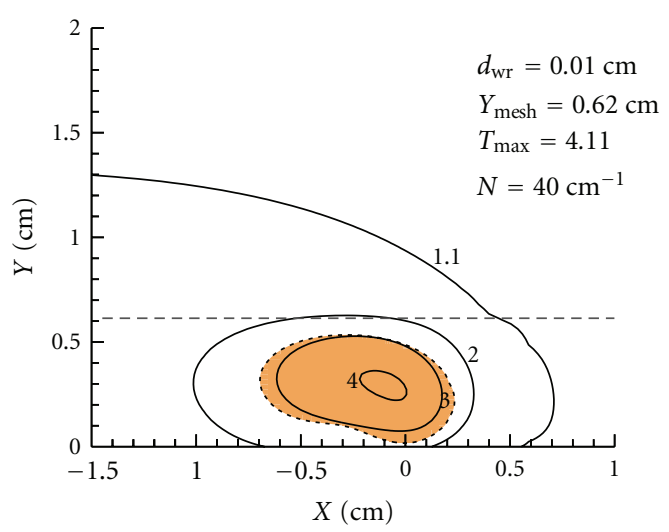

(b)

Figure 6: Effect of $N$ on flame size and temperature field. (a) $Y_{\text {mesh }}=0.75 \mathrm{~cm}$ and (b) $Y_{\text {mesh }}=$ near extinction. The dashed line represents wire mesh. 


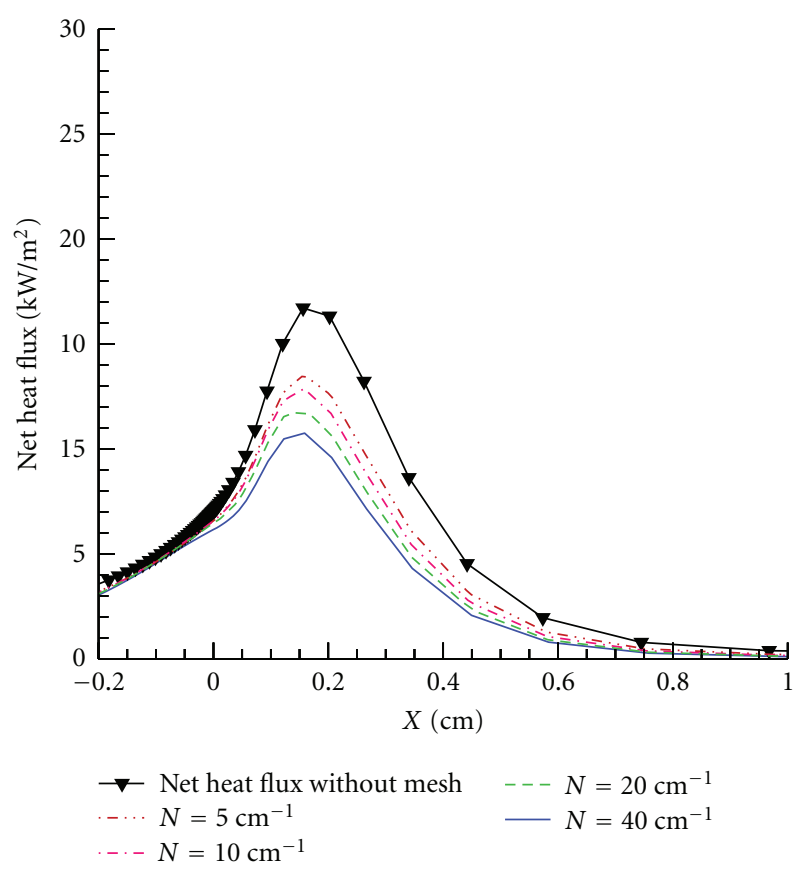

(a)

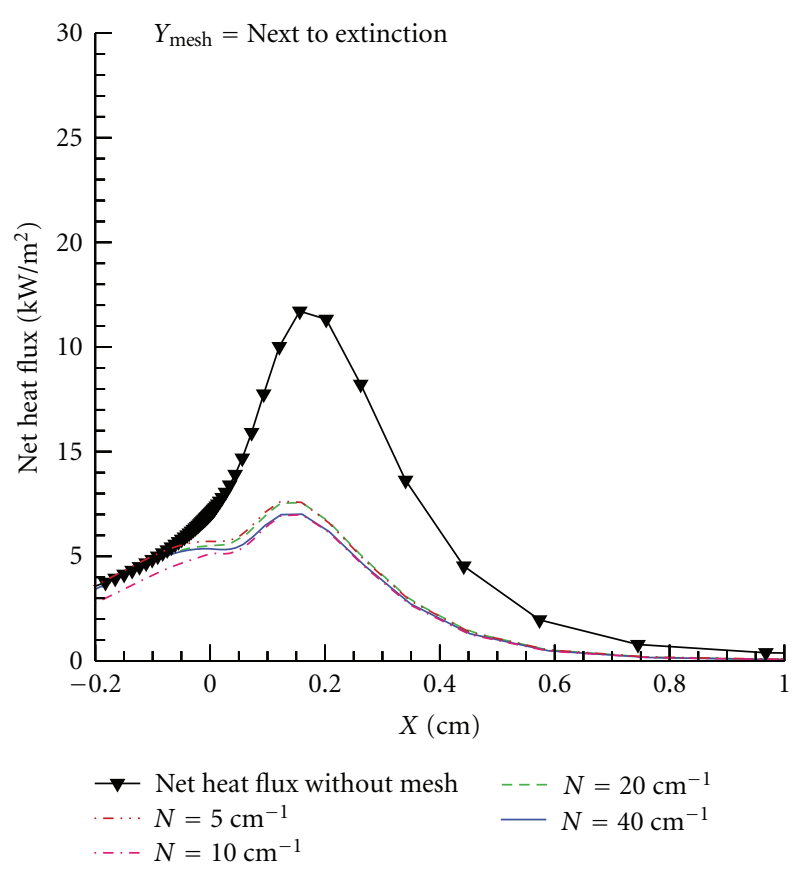

(b)

Figure 7: Effect of $N$ on net heat flux. (a) $Y_{\text {mesh }}=0.75 \mathrm{~cm}$ and (b) $Y_{\text {mesh }}=$ near extinction.

at the surface and their diffusivities are not known, hence, the fuel Lewis number remains an unknown quantity. The effect of fuel Lewis number has been studied [26] by varying fuel Lewis number over a wide range (0.1 to 3$)$. The flame location was reported to shift with the change in Lewis number. However, the maximum shift above the fuel surface was of the order of $1 \mathrm{~mm}$. So, while small quantitative change in the results due to fuel Lewis number is expected, the qualitative trend is expected to remain the same.

\section{Abbreviations}

$\bar{A}_{s}$ : Solid-phase preexponential factor $\left(1.9 \times 10^{7} \mathrm{~cm} / \mathrm{s}\right)$

$A_{w}$ : Wire mesh area

$\bar{B}_{g}:$ Gas-phase preexponential factor $\left(1.58 \times 10^{9} \mathrm{~m}^{3} / \mathrm{Kg} / \mathrm{s}\right)$

$c_{P}^{*}$ : Reference gas-phase specific heat $(0.33 \mathrm{cal} / \mathrm{g} / \mathrm{K})$

$c_{P}$ : Nondimensional gas-phase specific heat $\left(=\bar{c}_{P} / c_{P}^{*}\right)$

$\bar{c}_{s}: \quad$ Solid-phase specific heat $(0.3 \mathrm{cal} / \mathrm{g} / \mathrm{K})$

$c: \quad c_{P}^{*} / \bar{c}_{s}(=1.1)$

$C: \quad$ Correction factor

$C_{p, i}$ : Nondimensional specific heat for specie $i$

Da: Damkohler number

$D_{i}$ : Diffusion coefficient of specie $i$

$\bar{d}_{\mathrm{wr}}$ : Mesh wire diameter

$\bar{E}_{g}$ : Gas-phase activation energy $\left(2.086 \times 10^{-4} \mathrm{cal} / \mathrm{gmol}\right)$
$E_{g}$ : Nondimensional gas-phase activation energy $\left(=\bar{E}_{g} / \bar{R}_{u} / \bar{T}_{\infty}=35\right)$

$\bar{E}_{s}$ : Solid-phase activation energy $\left(3.274 \times 10^{3} \mathrm{cal} / \mathrm{gmol}\right)$

$E_{s}$ : Nondimensional solid-phase activation energy $\left(=\bar{E}_{s} / \bar{R}_{u} / \bar{T}_{\infty}=55\right)$

$f_{i}$ : Stoichiometric mass ratio of species $i$ and fuel

$\bar{g}_{e}$ : Gravitational acceleration on surface of Earth $\left(\bar{g}_{e}=981 \mathrm{~cm} / \mathrm{s}^{2}\right)$

$\bar{g}$ : Gravitational acceleration

g: Gravitational acceleration $\left(\bar{g} / \bar{g}_{e}\right)$

$h_{i}$ : Enthalpy of specie $i$

$h_{s}$ : Nondimensional solid fuel thickness $\left(=\bar{h}_{s} / \bar{L}_{R}\right)$

$h$ : Nondimensional fuel thickness $(\bar{h} / \bar{\tau})$

K: Absorptivity of the medium

Le: Lewis number of species $I\left(\mathrm{Le}_{F}=1, \mathrm{Le}_{\mathrm{O}_{2}}=\right.$ $1.11, \mathrm{Le}_{\mathrm{CO}_{2}}=1.39, \mathrm{Le}_{\mathrm{H}_{2} \mathrm{O}}=0.83, \mathrm{Le}_{\mathrm{N}_{2}}=1$ )

$\bar{l}_{P}:$ Pyrolysis length

$\bar{l}_{\mathrm{ph}}$ : Preheat length

$\bar{L}_{R}$ : Reference length (gas-phase thermal length, $\alpha^{*} / \bar{U}_{R}$ )

$\bar{L}_{s}$ : Reference length (solid-phase thermal length, $\bar{\alpha}_{s} / V_{F}$ )

$L$ : Nondimensional latent heat of solid $\left(\bar{L} / \bar{c}_{s} / \bar{T}_{\infty}=-2\right)$

$L_{w}$ : Length of wire

$M_{i}$ : Molecular weight of species $i$

$\dot{m}$ : Nondimensional mass flux from solid $\left(=\dot{m} / \rho^{*} / \bar{U}_{R}\right)$ 
$N$ : $\quad$ Number of wires per unit length

$P: \quad$ Nondimensional pressure $\left(=\left(\bar{P}-\bar{P}_{\infty}\right) / \rho^{*} / \bar{U}_{R}^{2}\right)$

$P_{l}: \quad$ Planck number

$\bar{P}_{\infty}: \quad$ Ambient pressure

Pr: $\quad$ Prandtl number

$Q_{\text {Sink: }} \quad$ Heat taken by mesh

$q_{c}$ : $\quad$ Conduction heat flux

$q_{r}: \quad$ Radiative heat flux

$q_{r}^{y+}, q_{r}^{y-}$ : Positive and negative components of $q_{r}$ in $y$-direction

$q_{r}^{y}$ : $\quad$ Net radiative heat flux in $y$-direction

$q^{x+}, q_{r}^{x-}$ : Positive and negative components of $q_{r}$ in $x$-direction

$q_{r}^{x}: \quad \quad \quad$ Net radiative heat flux in $x$-direction

Re: $\quad$ Reynolds number

$\bar{R}_{u}$ : $\quad$ Universal gas constant

Ra: Rayleigh number

$T^{*}$ : $\quad$ Reference temperature $(1250 \mathrm{~K})$

$T: \quad$ Nondimensional gas temperature $\left(=\bar{T} / \bar{T}_{\infty}\right)$

$\bar{T}_{\infty}: \quad$ Ambient temperature $(300 \mathrm{~K})$

$T_{L}$ : $\quad$ Nondimensional temperature at which $L$ is given $\left(=\bar{T}_{L} / \bar{T}_{\infty}=1\right)$

$T_{s}$ : $\quad$ Nondimensional solid temperature $\left(=\bar{T}_{s} / \bar{T}_{\infty}\right)$

$\bar{T}_{\text {surface: }}$ Temperature of wire mesh

$T_{\text {gas }}$ : Nondimensional gas temperature

$\bar{U}_{B}: \quad$ Reference buoyant velocity

$\bar{U}_{R}: \quad$ Reference velocity $\left(\max \left(\bar{U}_{\infty}+\bar{U}_{B}\right)\right)$

$\bar{U}_{\infty}: \quad$ Forced flow velocity

$u: \quad$ Nondimensional velocity in $x$-direction $\left(=\bar{u} / \bar{U}_{R}\right)$

$v$ : $\quad$ Nondimensional velocity in $Y$-direction $\left(=\bar{v} / \bar{U}_{R}\right)$

$V_{f}: \quad$ Flame spread rate

$x, X: \quad$ Nondimensional $x$-coordinate $\left(=\bar{x} / \bar{L}_{R}\right)$

$X_{i}$ : $\quad$ Mole fraction of specie $i$

$y, Y: \quad$ Nondimensional $y$-coordinate $\left(=\bar{y} / \bar{L}_{R}\right)$

$Y_{i}: \quad$ Mass fraction of specie $i$

$Y_{\text {mesh }}$ : Mesh location.

\section{Greek Symbols}

$\alpha^{*}$ : Reference gas thermal diffusivity $\left(2.13 \mathrm{~cm}^{2} / \mathrm{s}\right)$

$\bar{\alpha}_{s}$ : Reference solid thermal diffusivity

$\varepsilon$ : Solid emittance (0.92)

$\alpha$ : Solid absorptance (0.92), gas absorption coefficient

$\kappa^{*}$ : Reference gas thermal conductivity $\left(1.93 \times 10^{-4} \mathrm{cal} / \mathrm{c} \mathrm{m} / \mathrm{s} / \mathrm{K}\right)$

$\kappa$ : Nondimensional gas thermal conductivity $\left(=\bar{k} / k^{*}\right)$

$\mu^{*}$ : Reference gas viscosity $\left(4.1 \times 10^{-4} \mathrm{~g} / \mathrm{cm} / \mathrm{s}\right)$

$\mu$ : Nondimensional gas viscosity $\left(=\bar{\mu} / \mu^{*}\right)$

$\rho^{*}$ : Reference gas density $\left(2.75 \times 10^{-4} \mathrm{~g} / \mathrm{cm}^{3}\right)$

$\rho: \quad$ Non dimensional gas density $\left(=\bar{\rho} / \rho^{*}\right)$ $\bar{\rho}_{\infty}: \quad$ Ambient gas density $\left(1.15 \times 10^{-3} \mathrm{~g} / \mathrm{cm}^{3}\right)$

$\bar{\rho}_{s}: \quad$ Solid fuel density $\left(0.75 \mathrm{~g} / \mathrm{cm}^{3}\right)$

$\kappa: \quad$ Stefan-Boltzmann constant $\left(1.356 \times 10^{-12} \mathrm{cal} / \mathrm{cm}^{2} / \mathrm{s} / \mathrm{K}^{4}\right)$

$\bar{\tau}$ : $\quad$ Solid half-thickness $\left(3.8 \times 10^{-3} \mathrm{~cm}\right)$

$\omega_{F}^{\prime \prime \prime}: \quad$ Nondimensional fuel source term $\left(=-D a \rho^{2} Y_{F} Y_{\mathrm{O}_{2}} \exp \left(-E_{g} / T\right)\right)$

$\omega_{i}^{\prime \prime \prime}$ : Sink or source term for species $i\left(=f_{i} \omega_{F}^{\prime \prime \prime}\right)$

$\beta$ : $\quad$ Extinction coefficient

$\omega: \quad$ Scattering albedos

$\xi, \eta, \mu$ : Direction cosines in $x, y$ and $z$ directions

$\Omega: \quad$ Ordinate direction $(\xi, \eta, \mu)$

$\Gamma$ : $\quad$ Nondimensional solid parameter $\left(=\bar{\rho}_{s} \bar{c}_{s} \bar{V}_{F} / \rho^{*} / c_{P}^{*} / \bar{U}_{R}\right)$.

Subscripts

$f: \quad$ Flame

$i$ : $\quad$ Species $i(i=1, N)$

$B$ : Refers to buoyant

$F$ : $\quad$ Refers to fuel

L: $\quad$ Refers to latent heat

Max: Maximum

Min: Minimum

$s: \quad$ Solid phase

p: Pyrolysis

$g$ : Gas phase

$W: \quad$ Wire mesh

$x$ : $\quad$ Along $x$-direction, or derivative with respect to $x$

$y$ : Along $y$-direction, or derivative with respect to $y$

$R, r$ : Reference

$w: \quad$ Value at wall

$\infty$ : Value at far field.

\section{Superscripts}

*: Evaluated at $T^{*}$

—: Dimensional quantity.

\section{References}

[1] J. N. De Ris, "Spread of a laminar diffusion flame," Symposium (International) on Combustion, vol. 12, no. 1, pp. 241-252, 1969.

[2] F. A. Lastrina, R. S. Magee, and R. F. McAlevy III, "Flame spread over fuel beds: solid-phase energy considerations," Symposium (International) on Combustion, vol. 13, no. 1, pp. 935-948, 1971.

[3] W. A. Sirignano, "A critical discussion of theories of flame spread across solid and liquid fuels," Combustion Science and Technology, vol. 6, no. 1-2, pp. 95-105, 1972.

[4] S. R. Ray, Flame spread over solid fuels [Ph.D. thesis], Princeton University, 1981.

[5] A. C. Fernandez-Pello and S. T. Hirano, "Controlling mechanisms of flame spread," Combustion Science and Technology, vol. 32, pp. 1-33, 1983.

[6] I. S. Wichman, "Theory of opposed-flow flame spread," Progress in Energy and Combustion Science, vol. 18, no. 6, pp. 553-593, 1992.

[7] W. A. Sirignano and D. N. Schiller, "Mechanisms of flame 
spread across condensed phase fuels," in Physical and Chemical Aspects to Combustion, F. L. Dryer and R. F. Sawyer, Eds., pp. 353-407, Gordon and Breach Science Publishers, 1997.

[8] S. L. Olson, F. J. Miller, S. Jahangirian, and I. S. Wichman, "Flame spread over thin fuels in actual and simulated microgravity conditions," Combustion and Flame, vol. 156, no. 6, pp. 1214-1226, 2009.

[9] X. Zhang and Y. Yu, "Experimental studies on the threedimensional effects of opposed-flow flame spread over thin solid materials," Combustion and Flame, vol. 158, no. 6, pp. 1193-1200, 2011.

[10] C. Kumar and A. Kumar, "On the role of radiation and dimensionality in predicting flow opposed flame spread over thin fuels," Combustion Theory and Modelling, vol. 16, no. 3, pp. 537-569, 2012.

[11] C. Kumar and A. Kumar, "Opposed flow flame spread over thin solid fuels: a 2D numerical study on flame-spread transition from normal gravity to zero gravity and vice versa," International Journal of Aerospace Innovations, vol. 1, pp. 175187, 2009.

[12] A. Kumar, A numerical model of opposed flow flame spread over thin solid fuels [Ph.D. thesis], Case Western Reserve University, Cleveland, Ohio, USA, 2004.

[13] M. D. Smooke and V. Giovangigli, Formulation of the Premixed and Nonpremixed Test Problem, vol. 384 of Lecture Notes in Physics, chapter 1, Springer, New York, NY, USA, 1991.

[14] R. K. Rajput, Heat and Mass Transfer, S. Chand \& Company, New Delhi, India, 2001.

[15] S. Bhattacharjee and R. A. Altenkirch, "A comparison of theoretical and experimental results in flame spread over thin condensed fuels in a quiescent, microgravity environment," Symposium (International) on Combustion, vol. 24, no. 1, pp. 1669-1676, 1992.

[16] K. Tolejko, J. Kleinhenz, A. Kumar, R. Pettegrew, and J. S. T'ien, "Downward flame spread over a composite thin solid: comparison of experimental and model results," in Proceedings of the 4th Joint Meeting of U.S Sections of the Combustion Institute, 2005.

[17] D. Balsara, "Fast and accurate discrete ordinates methods for mutlidimensional radiative transfer. Part I, basic methods," Journal of Quantitative Spectroscopy and Radiative Transfer, vol. 69, no. 6, pp. 671-707, 2001.

[18] H. Bedir, J. S. T'ien, and H. S. Lee, "Comparison of different radiation treatments for a one-dimensional diffusion flame," Combustion Theory and Modelling, vol. 1, no. 4, pp. 395-404, 1997.

[19] J. L. Rhatigan, H. Bedir, and J. S. T'ien, "Gas-phase radiative effects on the burning and extinction of a solid fuel," Combustion and Flame, vol. 112, no. 1-2, pp. 231-241, 1998.

[20] C. L. Tien, "Thermal radiation properties of gases," in Advances in Heat Transfer, T. F. Irvine Jr, and J. P. Hartnett, Eds., vol. 5, pp. 234-254, Academic Press, New York, NY, USA, 1968.

[21] S. V. Patankar, Numerical Heat Transfer and Fluid Flow, Hemisphere, New York, NY, USA, 1980.

[22] I. S. Wichman, "Theory of opposed-flow flame spread," Progress in Energy and Combustion Science, vol. 18, no. 6, pp. 553-593, 1992.

[23] V. Malhotra and A. Kumar, "Effect of gas phase heat sink on suppression of downward flame spread over thin solid fuels," International Journal of Advances in Engineering Sciences and Applied Mathematics, vol. 4, no. 3, pp. 138-151, 2012.

[24] G. Grayson, K. R. Sacksteder, P. V. Ferkul, and J. S. T’ien, "Flame spreading over a thin solid in low-speed concurrent flow-drop tower experimental results and comparison with theory," Microgravity Science and Technology, vol. 7, no. 2, pp. 187-195, 1994.

[25] M. K. Wolverton, R. A. Altenkirch, and L. Tang, "Implementing multi-step chemical kinetics models in opposed-flow flame spread over cellulose and a comparison to single-step chemistry," Combustion and Flame, vol. 118, no. 1-2, pp. 281292, 1999.

[26] K. Tolejko, I. I. Feier, and J. S. T'ien, "Effects of fuel Lewis number on flame spread over solids," Proceedings of the Combustion Institute, vol. 30, no. 2, pp. 2263-2270, 2005. 

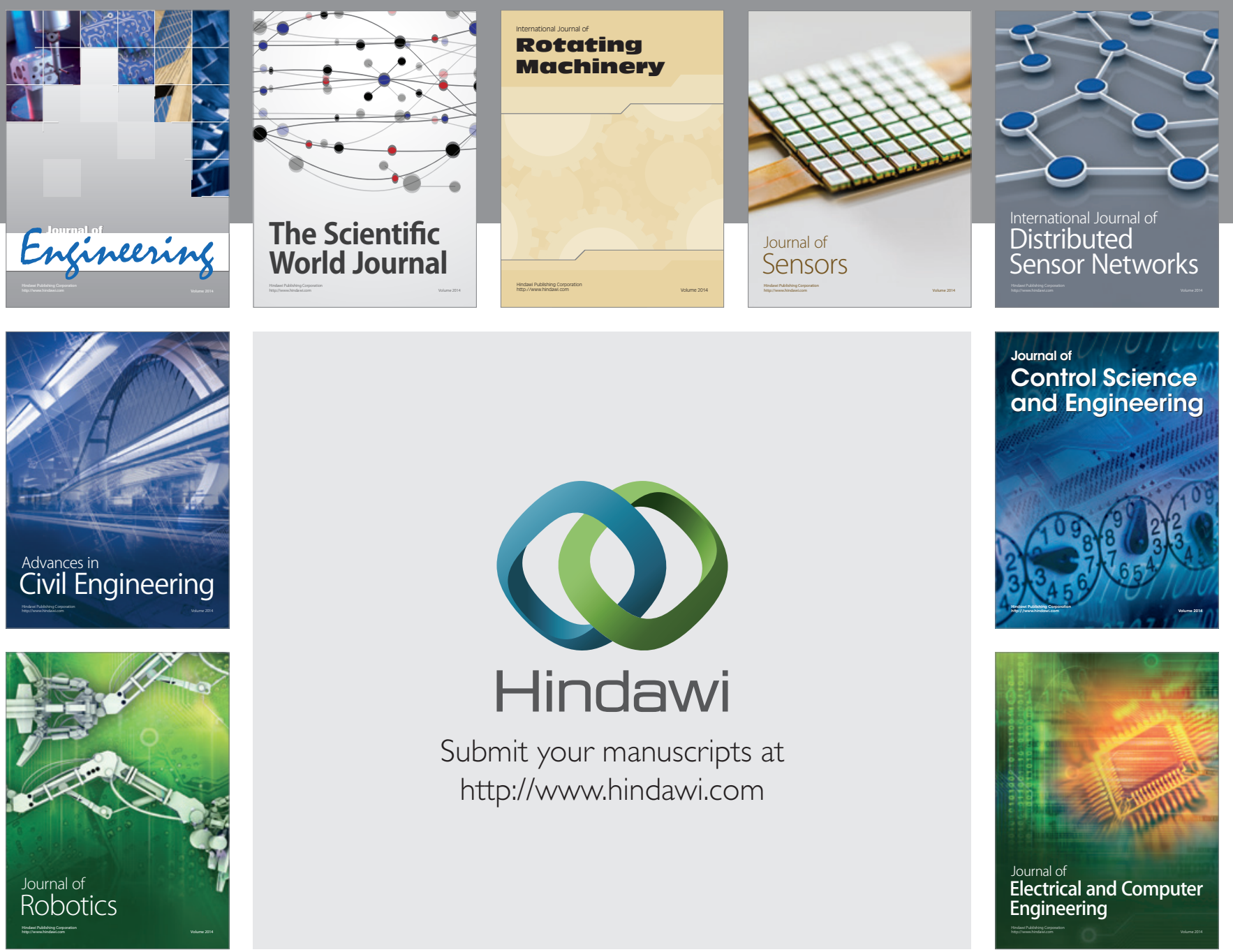

Submit your manuscripts at

http://www.hindawi.com
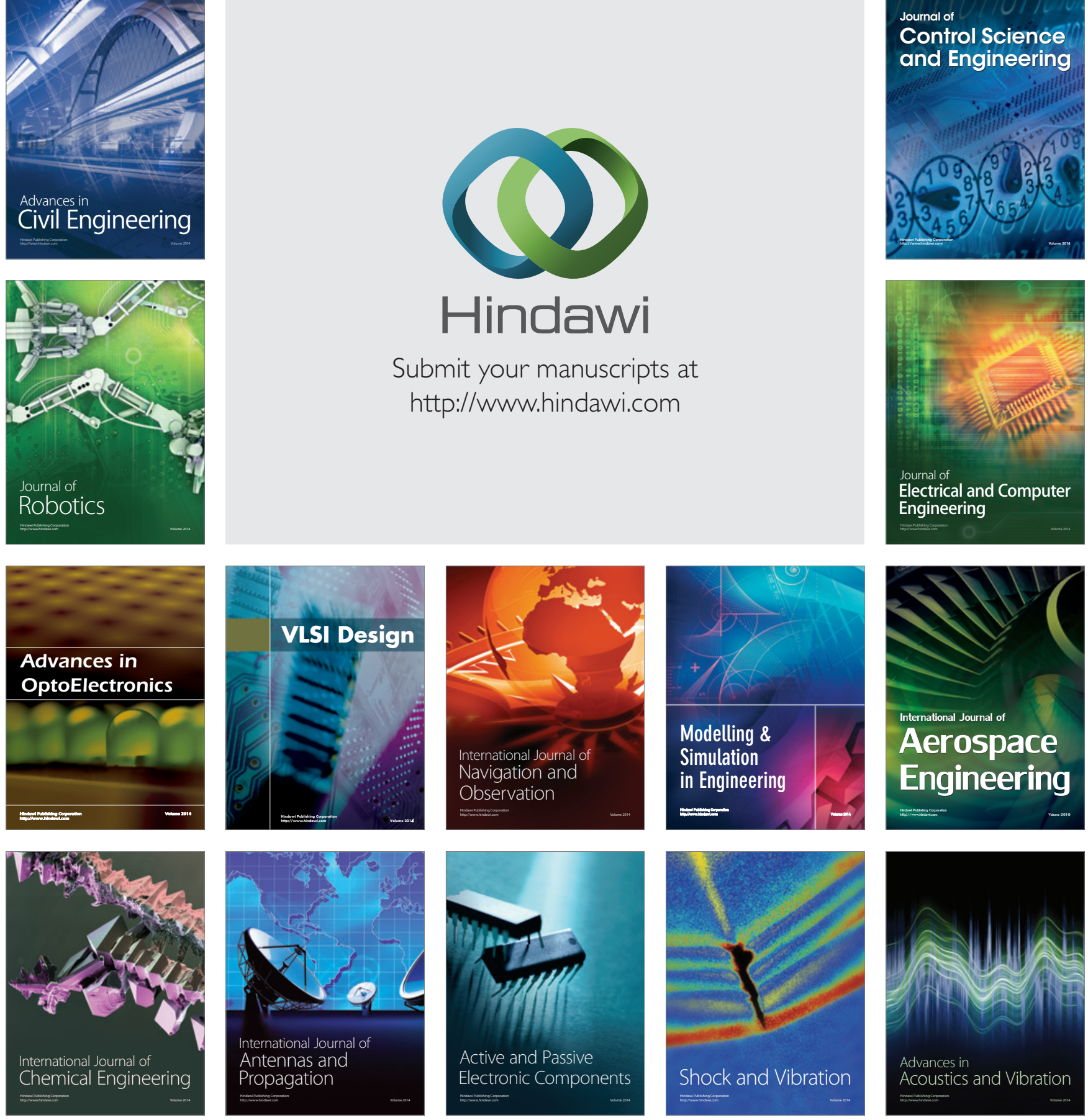